\title{
Green Synthesis of Iron Nanoparticles by Aqueous Extract of Eriobotrya japonica Leaves as a Heterogeneous Fenton-like Catalyst: Degradation of Basic Red 46
}

\author{
Emel Simla Önal, Tolga Yatkin, Memduha Ergüt, and Ayla Özer
}

\begin{abstract}
In the present study, iron nanoparticles (FeNPs) were synthesized by using aqueous extract of Eriobotrya japonica leaves. The synthesized FeNPs were characterized by DLS, XRD, FTIR, and SEM/EDX techniques. The characterization studies showed that, the prepared FeNPs were irregular spherical particles and mainly consist of maghemite $\left(\gamma-\mathrm{Fe}_{2} \mathrm{O}_{3}\right)$, magnetite $\left(\mathrm{Fe}_{3} \mathrm{O}_{4}\right)$, and iron oxohydroxide $(\mathrm{FeOOH})$ structures. Subsequently, the synthesized FeNPs were utilized as a heterogeneous catalyst for decolourisation of a toxic azo-dyestuff, Basic Red 46, with Fenton-like degradation in the presence of $\mathrm{H}_{2} \mathrm{O}_{2}$. BR 46 decolourisation was measured spectrophotometrically and expressed in terms of the decrease in UV-vis absorbance. FeNPs have high colour removal efficieny for BR 46 from aqueous solution. The effects of process parameters such as initial dye concentrations $(100-5000 \mathrm{mg} / \mathrm{L})$ and catalyst (FeNPs) concentrations ( $0.25-5 \mathrm{~g} / \mathrm{L})$ on Fenton-like degradation were investigated in a batch system. For Fenton-like degradation of BR 46 at room temperature, the optimum initial BR 46 concentration and FeNPs concentration were determined as $500 \mathrm{mg} / \mathrm{L}$ of and $0.5 \mathrm{~g} / \mathrm{L}$, respectively. Moreover, the possible Fenton-like decolourisation mechanism of Basic Red 46 was proposed. The suggested mechanism was based on the adsorption of Basic Red 46 on the surface of FeNPs, decomposition of $\mathrm{H}_{2} \mathrm{O}_{2}$, and formation of hydroxyl radicals and finally, oxidation of Basic Red 46.
\end{abstract}

Index Terms-Basic Red 46, decolourisation, green synthesis, heterogeneous fenton-like catalyst, iron nanoparticles.

\section{INTRODUCTION}

Dye pollutants used in various industries such as especially textile, printing, paper, leather, cosmetic, pharmaceutical, food, chemical paint, and varnish industries; are one of the major sources of environmental contamination [1].

Dye molecules consist of color bearing groups such as an aromatic structure called chromophore absorbing visible light and an auxochromes include $-\mathrm{NH}_{3},-\mathrm{COOH},-\mathrm{HSO}_{3}$, and $-\mathrm{OH}$ which can increase strength for bonding to fibres and support for water solubility [2], [3]. Moreover dyes can be classified as acid, basic, direct, dispersive, reactive, mordant, sulphur, and vat dyes according to mode of operation in textile industry. Azo-dyes are the most important and largest group of dyes constituting about $70 \%$ of the total dyes used for coloring [3]. They are posses one or more azo groups $(-\mathrm{N}=\mathrm{N}-)$, which form bridges between two or more

Manuscript received July 5, 2017; revised September 19, 2017.

Emel Simla Önal, Tolga Yatkin, Memduha Ergüt and Ayla Özer are with the Faculty of Chemical Engineering, Mersin University, Çiftlikköy Campus, Yenişehir, Mersin TR33343, Turkey (e-mail: simtoga31@gmail.com, memduha.ergut@gmail.com, ayozer@mersin.edu.tr ). aromatic rings [3].

There are 100,000 different kinds of dyes available commercially and textile industry uses $10 \%$ of them. The world wide annual production of dyes is over $7 \times 10^{5}$ tons and $10-15 \%$ of them are discharged the water sources through industrial pollutants [2], [4]. Discharge of dye-stuffs into the natural streams not only may be toxic to the aquatic lives due to the the presence of various metals and chlorides in them, but also; the presence of very small amounts (less than 1 ppm for some dyes) of dyes in water is highly visible and undesirable for any use. Color also, reduces photosynthetic activity as it can inhibit the sunlight penetration into the streams. In addition; the most of the dye effluents are assessed as toxic, mutagenic, and carcinogenic as well as they are recalcitrant, non-biodegradable, resistant to aerobic digestion; and stable to light, heat and oxidizing agents due to the complex chemical structure of them [4]-[6].

Therefore; several physical, chemical, and biological treatment methods such as adsorption, ion-exchange, photocatalysis, membrane separation, coagulation, electrocoagulation, and wet air oxidation have been used to eliminate these harmful effects of dye effluents but these methods are restricted from generation of toxic chemical sludge in consequence of they just transfer the contaminants from the wastewater to the solid phase, high operational cost of some, and their limited applicability [1], [3], [7].

In recent years, advanced oxidation processes (AOPs) such as Fenton's reagent $\left(\mathrm{H}_{2} \mathrm{O}_{2}, \mathrm{Fe}^{2+}\right)$ photocatalytic oxidation, photo-Fenton, electro-Fenton, $\mathrm{UV} / \mathrm{H}_{2} \mathrm{O}_{2}$, and ozonation processes which are based on the production and the oxidative action of hydroxyl radicals have gained great attention in order to degrade various toxic organic compounds like azo dyes [4], [5].

Fenton-type reactions in the presence of $\mathrm{H}_{2} \mathrm{O}_{2}$ as an oxidant and iron ions at acidic $\mathrm{pH}$ have been among the most common homogeneous advanced oxidation processes. The basic advantage of Fenton's reaction is ease of operation and maintainability and it is an inexpensive source of hydroxyl radicals. It is particularly advantageous when the wastewater contains suspended solids at high levels due to the limited photon penetration. Moreover, narrow working $\mathrm{pH}$ range and trouble of separation and recovery of the iron species are among the disadvantages of traditional Fenton reactions [8]. Thus, studies on Fenton-like reactions or iron-bearing materials-based heterogeneous Fenton reactions have been gradually attracted more attention.

Various studies have been reported on green and/or chemical synthesized iron nanoparticles such as zero valent 
iron, iron oxides (e.g., $\alpha-\mathrm{Fe}_{2} \mathrm{O}_{3}, \mathrm{Fe}_{3} \mathrm{O}_{4}, \alpha$ and $\gamma$-FeOOH), iron-containing bimetallic nanoparticles (e.g., Fe/Pd-NPs, $\mathrm{Fe} / \mathrm{Ni}-\mathrm{NPs}$ ) and iron-containing porous catalysts such as zeolites, clays, resins, mesoporous materials were tested for heterogeneous Fenton-type degradation of organic pollutants in aqueous environments [2], [9]-[11].

The use of plant leaves extracts is a promising approach for preparing iron nanoparticles. It is reported that loquat leaves have many bioactive components such as; phenols, flavonoids, triterpene acids and polysaccharides [12], so; their extracts could be used as a bioreductant for preparing iron nanoparticles owing to their reducing capability of iron salts. On the contrary of commonly used chemical reduction method which is based on the reaction iron salts with sodium borohydride, plants extracts are considered to be cost-effective, non-toxic and safer for the environment than sodium borohydride because, sodium borohydride is regarded an expensive and toxic compound which is therefore may be leads to contamination upon application [2], [11].

In the present study, iron nanoparticles were firstly synthesized as a Fenton-like catalyst using aqueous extract of Eriobotrya japonica leaves. Subsequently; the size, morphology, composition, and structure of prepared nanoparticles were determined by characterization studies. Finally, they were used for the decolourisation of Basic Red 46 dye in a Fenton-like heterogeneous system. The decolourisation experiments were carried out in a batch system and the main process parameters were investigated.

\section{MATERIALS AND METHODS}

\section{A. Materials}

All of the chemicals were of analytical grade and they were used without further purification. For synthesis of FeNPs, $\mathrm{FeSO}_{4} .7 \mathrm{H}_{2} \mathrm{O}$ was supplied from Carlo Erba, aceton (> 99.5\%) and $\mathrm{H}_{2} \mathrm{O}_{2}(30 \%)$ were provided from Merck. Basic Red 46 (BR 46) dyestuff was supplied by Dye Star with commercial name is Astrazone Red FBL. BR 46 was of commercial purity (Type: Cationic, Mw: $322 \mathrm{~g} / \mathrm{mol}, \lambda \max : 530 \mathrm{~nm})$. The chemical structure of BR 46 was shown in Fig. 1.

A stock solution of $1000 \mathrm{mg} / \mathrm{L}$ of BR 46 was first prepared and then the desired BR 46 concentrations were prepared by appropriate dilutions from stock dye solution. Also, a $10.0 \%$ $\mathrm{H}_{2} \mathrm{O}_{2}$ solution (v/v) was prepared from a stock $30.0 \% \mathrm{H}_{2} \mathrm{O}_{2}$ solution by dilution with deionized water.

\section{B. The Preparation of FeNPs}

The green synthesis of iron nanoparticles using Loquat (Eriobotrya japonica) leaves extracts was carried out reported by Shahwan et al. [13], with modifications .

Loquat (Eriobotrya japonica) leaves were collected from loquat trees grown in Mersin, Turkey. Aqueous extract of E. japonica leaves was prepared by heating the certain amount of air-dried leaves as it's concentration will be $60 \mathrm{~g} / \mathrm{L}$ (500 $\mathrm{ml}$ of distilled water) at $100^{\circ} \mathrm{C}$ for $1 \mathrm{~h}$. Subsequently, the filtered aqueous extract was added to $0.1 \mathrm{~mol} / \mathrm{L} \mathrm{FeSO}_{4} \cdot 7 \mathrm{H}_{2} \mathrm{O}$ solution in 1:1 volume ratio and the final mixture was kept under vigorous stirring for $3 \mathrm{~h}$.

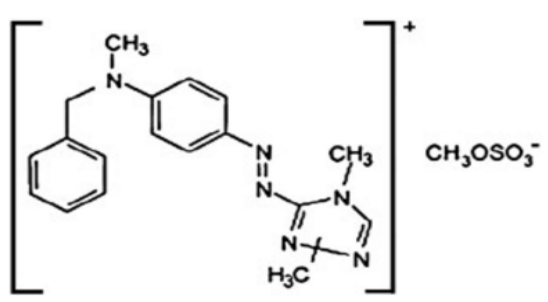

Fig. 1. Chemical structure of BR 46.

The immediate changing of the colour of the solution from clear to intense black indicated the formation of FeNPs. The formed nanoparticles were separated by evaporating water from solution on a hot plate and then collected nanoparticles, washed several times with deionized water and dried in an oven at $120^{\circ} \mathrm{C}$ overnight.

\section{The Characterization of Green Synthesized FeNPs}

The mean hydrodynamic particle size and size distribution of FeNPs were measured by dynamic light scattering (DLS) analysis with the Malvern Zetasizer. The functional groups of FeNPs before and after decolourisation were determined by Fourier transform infrared spectrometer (FT-IR) in the range of $4000-400 \mathrm{~cm}^{-1}$. Crystal structure was observed by XRD analysis, using nickel-filtered $\mathrm{Cu} \mathrm{K} \alpha$ radiation in a Philips XPert MPD apparatus operated at $40 \mathrm{kV}$ and $30 \mathrm{~mA}$, in the $2 \theta$ range of $10^{\circ}-80^{\circ}$. The morphology of the FeNPs was analyzed by Zeiss/Supra 55 SEM analysis and elemental identification and quantitative compositional information of the nanoparticle were determined by Zeiss/Supra 55 energy dispersive X-ray analyzer (EDX) pre- and post decolourisation.

\section{Heterogeneous Fenton-Like Decolourisation Experiments}

All the decolourisation experiments were conducted with Erlenmayer flasks ( $250 \mathrm{~mL}$ ) containing $100 \mathrm{~mL}$ of BR 46 dye solutions in a shaker that was adjusted $25^{\circ} \mathrm{C}$ of temperature and constant shaking rate. In the decolourisation experiments, $0.1 \mathrm{~g}$ of FeNPs, except for catalyst concentration experiments, was added to solutions containing $5.0 \mathrm{~mL}$ of $10.0 \% \mathrm{H}_{2} \mathrm{O}_{2}$ and $100 \mathrm{~mL}$ of $\mathrm{BR} 46$ solution at known initial dye concentrations and they were agitated in the water bath at constant temperature. The samples were taken at pre-determined time intervals and then were separated from the nanoparticles by a simple decantation. Subsequently, the UV-vis absorbance readings were performed in a spectrophotometer (Cheibos UV-vis model) The decolourisation percentage for BR46 was expressed in terms of the decrease in UV- vis absorbance and calculated with equation (1) as given follow:

$$
\% \mathrm{CR}=\left[\left(\left.A_{o}\right|_{530 \mathrm{~nm}}-\left.A_{t}\right|_{530 \mathrm{~nm}}\right) /\left.A_{o}\right|_{530 \mathrm{~nm}}\right] \times 100
$$

where CR (\%) represented the colour removal efficiency of FeNPs, $A_{o}$ was the initial absorbance of BR 46 at $t=0 \mathrm{~min}$, and $A_{t}$ was the absorbance of BR46 at $t$ min.

Moreover, to determine the decolourisation capacity of $\mathrm{H}_{2} \mathrm{O}_{2}$ for BR 46, the control experiments without FeNPs were carried out under the same experimental conditions.

Experiments were repeated to investigate the effects of 
different operation parameters on the dye decolourisation such as initial BR46 concentration $(100-5000 \mathrm{mg} / \mathrm{L})$ and FeNPs (catalyst) concentration $(0.5-3 \mathrm{~g} / \mathrm{L})$. The $\mathrm{pH}$ adjustment did not performed during the heterogeneousFenton process and the experiments carried out in the natural initial BR 46 solution pHs.

\section{RESULTS AND DiSCUSSIONS}

\section{A. The Characterization of Green Synthesized FeNPs}

Particle size distribution of the green synthesized FeNPs was done by DLS analysis and the results were presented in Fig. 2. As depicted in Fig. 2, particles were homogenously distributed and their mean hydrodynamic size was found to be $171.2 \mathrm{~nm}$ (PDI 0.217).

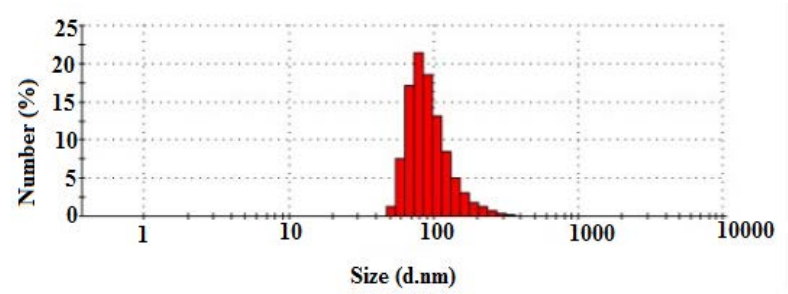

Fig. 2. Particle size distribution of FeNPs.

The XRD pattern of synthesized FeNPs was given in Fig. 3, the peaks obtained at $2 \theta=25.9^{\circ}, 28.3^{\circ}$ and $35.6^{\circ}$ correspond to maghemite $\left(\gamma-\mathrm{Fe}_{2} \mathrm{O}_{3}\right)$, magnetite $\left(\mathrm{Fe}_{3} \mathrm{O}_{4}\right)$, and iron oxohydroxide, respectively. Also, the intensity peak at $2 \theta=$ $17.56^{\circ}$ was identified to belongs to an organic material in polyphenols reported in literature [13], [14]. As can be seen from Fig. 3, the relatively weak peaks obtained in the XRD diagram indicated that the synthesized nanoparticles have amorphous parts [13]. Moreover, some studies in the literature have reported that the synthesized FeNPs by plant extracts are amorphous in nature [13], [14]. After Fenton-like reaction the XRD diagram of FeNPs indicated that the material was completely amorphous structure (figure not shown). The differences in the XRD patterns of FeNPs before and after Fenton-like reaction showed that the crystallinity and phase of the FeNPs completely changed.

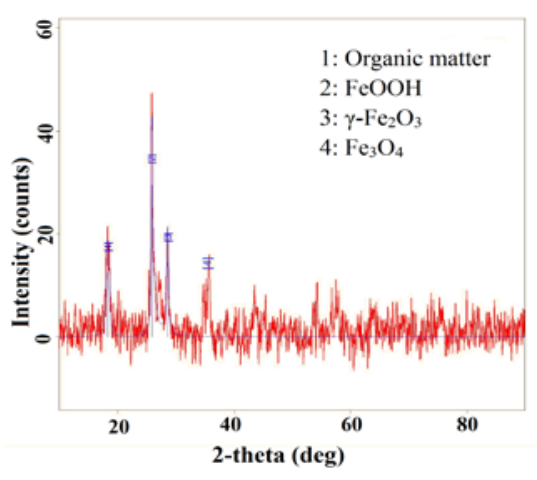

Fig. 3. XRD pattern of FeNPs.

The SEM images before and after Fenton-like degradation for the green synthesized FeNPs were shown in Fig. 4(a) and (b), respectively. As seen from, Fig. 4(a) the synthesized FeNPs are irregular spherical and porous morphology, indicating a chain structure with a diameter ranging from $30-$ $100 \mathrm{~nm}$.
Also, they are highly prone to agglomeration, therefore the mean hydrodynamic diameters of nanoparticles were found as higher than $100 \mathrm{~nm}$ by DLS analysis, this state may be due to the absorption effects and particle scattering because of agglomeration [15]. Similar agglomeration behavior of nanoparticles was reported by Truskewycz et al., 2016, [2] for iron nanoparticles synthesized by using green tea extract. The SEM images after Fenton like reaction (Fig. 4 (b)) showed that a non-porous and smooth surface may be due to the BR 46 and/or degradation products were adsorbed to the FeNPs surface and closed the pores of FeNPs. This result indicated that the morphology and structure of nanoparticles were changed after degradation experiments.
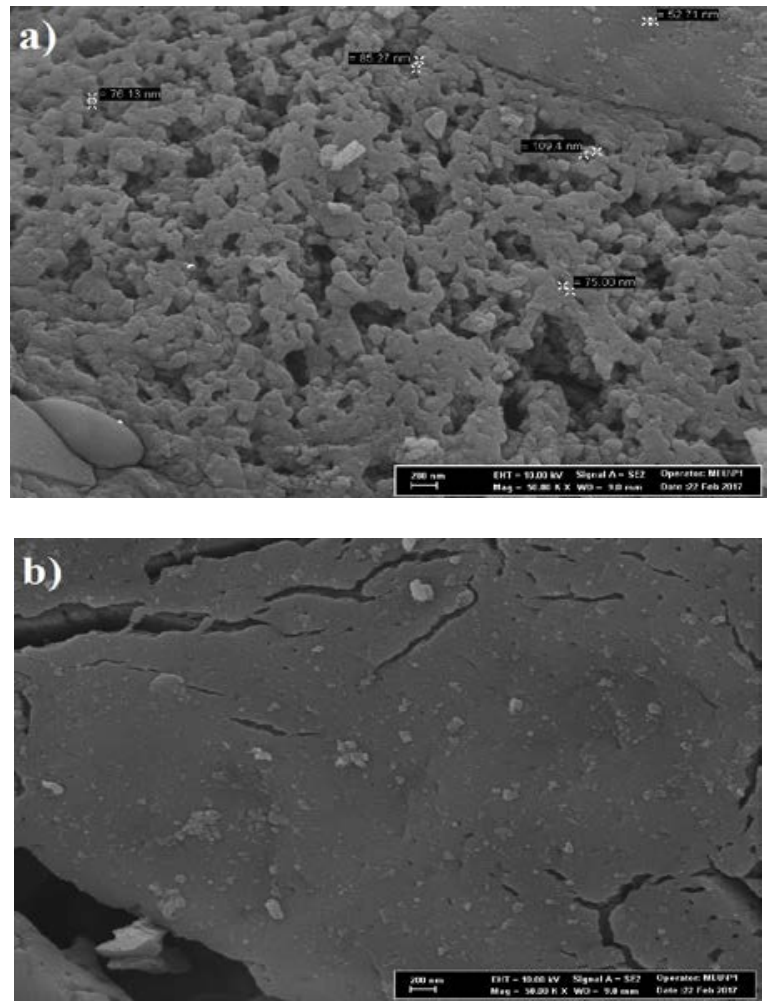

Fig. 4. The SEM images of FeNPs a) before b) after degradation.

Elemental analysis results for loquat leaves extract and FeNPs before and after Fenton-like process were given in Table I. According to Table I, the elemental and quantitative weight composition (wt.\%) of loquat (Eriobotrya japonica) leaves crude extract was composed of $37.47 \% \mathrm{O}, 42.22 \% \mathrm{C}$, $0.62 \% \mathrm{~S}, 8.83 \% \mathrm{~K}$ and $1.52 \% \mathrm{Mg}, 5.03 \% \mathrm{Ca}, 3.91 \% \mathrm{Cl}$ and $0.37 \%$ Si elements. The high $\mathrm{C}, \mathrm{O}$ and precious minerals content attributed to presence of polyphenolic compounds which are could be responsible for reduction of $\mathrm{Fe}^{2+}$ ions and formation of FeNPs. Moreover, the elemental composition of the synthesized FeNPs was composed of $28.70 \% \mathrm{Fe}$, $37.53 \%$ O, 18.31 \% C, $12.55 \%$ S, $2.642 \%$ K and $0.243 \%$ $\mathrm{Mg}$ elements. These results revealed that, the synthesized nanoparticles were mainly composed of Fe and $\mathrm{O}$ elements. And $\mathrm{C}, \mathrm{O}, \mathrm{K}$ and $\mathrm{Mg}$ elements were derived from aqueous leaves extract as mentioned above. Also, $\mathrm{S}$ element must be originating from not only extract but also $\mathrm{FeSO}_{4} \cdot 7 \mathrm{H}_{2} \mathrm{O}$ precursor used in synthesis procedure. The elemental compositon of FeNPs after decolourisation, as shown in Table I, showed that the percent weights (\%) of $\mathrm{C}$ and $\mathrm{O}$ increased, while the Fe content (wt.\%) decreased and the $\mathrm{N}$ 
element was appeared in structure. These results supported the XRD spectrum (Fig. 3) which was indicated that the synthesized FeNPs have amorphous parts, therefore FeNPs can be dissolve under the acid attack. Hereby; C, O and $\mathrm{N}$ elements originating from extract and BR 46 dye adsorbed on the catalyst (FeNPs) surface. FT-IR measurements were employed to investigate the possible functional groups responsible for the reduction of the metal precursors and formation of FeNPs and determine the structural changes of FeNPs after BR 46 decolourisation. The FT-IR spectrums of loquat (Eriobotrya japonica) leaves extract, the synthesized FeNPs before and after Fenton-like reaction were presented in Fig. 5, Fig. 6 (a) and Fig. 6 (b), respectively.

TABLE I: ELEMENTAL ANALYSIS RESULTS FOR LOQUAT LEAVES EXTRACT AND FENPS AT BEFORE AND AFTER DECOLOURISATION

\begin{tabular}{cccc}
\hline \hline \multicolumn{4}{c}{ Weight (\%) } \\
Element & $\begin{array}{c}\text { E. japonica } \\
\text { leaves extract }\end{array}$ & $\begin{array}{c}\text { Green } \\
\text { synthesized } \\
\text { FeNPs }\end{array}$ & $\begin{array}{c}\text { After Fenton- } \\
\text { like process }\end{array}$ \\
\hline $\mathrm{O}$ & 37.47 & 37.53 & 42.16 \\
$\mathrm{Fe}$ & - & 28.70 & 19.81 \\
$\mathrm{C}$ & 42.22 & 18.31 & 24.52 \\
$\mathrm{~S}$ & 0.62 & 12.55 & 8.253 \\
$\mathrm{~K}$ & 8.83 & 2.642 & 0.995 \\
$\mathrm{Mg}$ & 1.52 & 0.243 & 0.217 \\
$\mathrm{Ca}$ & 5.03 & - & - \\
$\mathrm{Cl}$ & 3.91 & - & 1.110 \\
$\mathrm{Si}$ & 0.37 & - & 0.652 \\
$\mathrm{~N}$ & - & - & 2.255 \\
\hline \hline
\end{tabular}

According to the FT-IR spectrum of loquat leaves extract (Fig. 5), the broad band at $3270.9 \mathrm{~cm}^{-1}$ is attributed to $\mathrm{O}-\mathrm{H}$ stretching vibration related to the phenolic compounds. The 2928 and $2187 \mathrm{~cm}^{-1}$ bands correspond to C-H stretching vibration of the $-\mathrm{CH}_{2}$ and $\mathrm{CH}_{3}$ functional groups [16], [17]. The band at $1720 \mathrm{~cm}^{-1}$ is identified as carbonyl groups from dimerized saturated aliphatic acids [18], $1595.36 \mathrm{~cm}^{-1}$ and $1378.12 \mathrm{~cm}^{-1}$ are due to $\mathrm{C}=\mathrm{O}, \mathrm{C}-\mathrm{O}$ and $\mathrm{O}-\mathrm{H}$ groups and the presence of $\mathrm{C}-\mathrm{O}$ stretching in carboxyl groups, respectively. The broad band at $1243 \mathrm{~cm}^{-1}$ corresponds to the C-O-C or $\mathrm{C}=\mathrm{O}$ stretching vibration and $1036 \mathrm{~cm}^{-1}$ band may be assigned to C-O-C and O-H absorption [18]. In the mean time, the bands observed at $889.03,763.93$ and $599.63 \mathrm{~cm}^{-1}$ are correspond to phenol groups and bending vibrations of aromatics, carboxylic acids and amides [16].

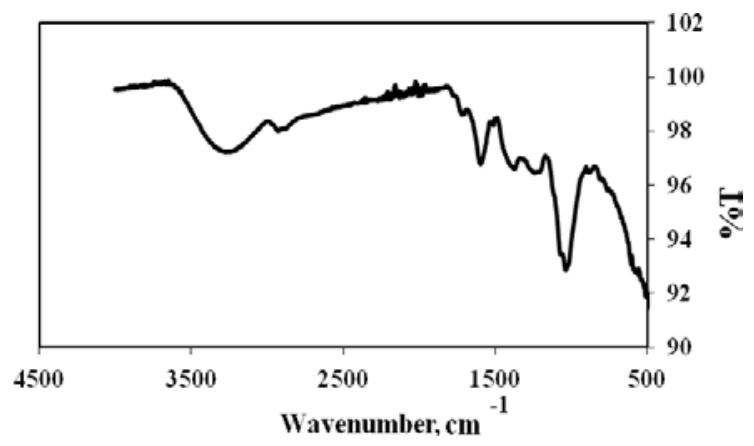

Fig. 5. FT-IR spectrum of loquat (Eriobotrya japonica) leaves extract.

These peaks demonstrating the presence of phenolic compounds could be probably responsible for the reduction of $\mathrm{Fe}^{2+}$ ions and formation of FeNPs.

In the FT-IR spectrum of green synthesized FeNPs was shown in Fig. 6 (a), many peaks were obtained associated with phenols, amines, carboxyl and carbonyl groups due to the leaf extract. The bands at 3236.66 and $2155 \mathrm{~cm}^{-1}$ correspond to $\mathrm{O}-\mathrm{H}$ group and $\mathrm{C}-\mathrm{H}$ stretching vibration of $-\mathrm{CH}_{2}$ and $\mathrm{CH}_{3}$ functional groups, respectively and the band at $1605 \mathrm{~cm}^{-1}$ attributed to $\mathrm{C}=\mathrm{O}$, and the strong peak at 1077 $\mathrm{cm}^{-1}$ due to $\mathrm{C}-\mathrm{O}$ stretching [19]. In addition, the absorption bands at $596 \mathrm{~cm}^{-1}$ and $458.88 \mathrm{~cm}^{-1}$ refer to $\mathrm{Fe}-\mathrm{O}$ stretches of $\mathrm{Fe}_{3} \mathrm{O}_{4}$ and $\mathrm{Fe}_{2} \mathrm{O}_{3}$ [20], confirming the formation FeNPs.

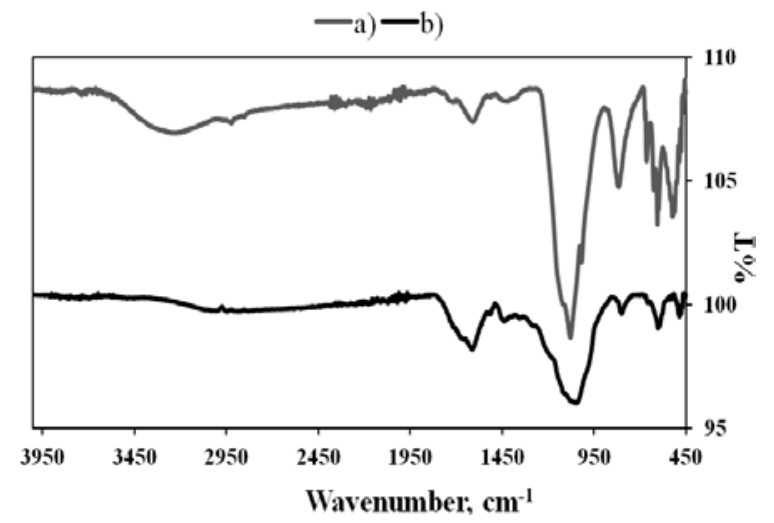

Fig. 6. FT-IR spectrum of FeNPs a) before b) after decolourisation.

The FT-IR spectrum for FeNPs after contact with BR 46 dye solution showed indicative bands at $2946.29 \mathrm{~cm}^{-1}$ and $1611.05 \mathrm{~cm}^{-1}$. These bands related to the stretching vibration of $\mathrm{C}-\mathrm{H}$ in the methyl groups and $\mathrm{C}-\mathrm{C}$ (aromatic ring) stretching vibration. On comparing the pre- and post decolourisation spectrum of FeNPs, two new absorbance bands at $1514.5 \mathrm{~cm}^{-1}$ and $1436.6 \mathrm{~cm}^{-1}$ were observed indicative of N-O stretch and C-H (bend) [1]. Also, as can be seen from Fig. 6 (a) and (b), the strong absorbance band at $3244.90 \mathrm{~cm}^{-1}$ disappeared, the absorbance bands at $1042 \mathrm{~cm}^{-1}$ and $600.88 \mathrm{~cm}^{-1}$ enlarged. These results showed that BR 46 and/or its degradation products were attached to the Fe NPs surface [13].

\section{B. Effects of Parameters on the Decolourisation of BR 46}

The catalytic performance of the FeNPs synthesized by the loquat leaves aqueous extract, was investigated in the heterogeneous Fenton-like degradation of an azo dye, Basic Red 46 (BR 46).

The degradation mechanism is based on the formation of highly reactive hydroxyl radicals $(\mathrm{OH} \bullet)$ by decomposition of $\mathrm{H}_{2} \mathrm{O}_{2}$ with $\mathrm{Fe}^{2+}$ ions. In the classical Fenton system, the generation cycle of hydroxyl radicals by Fenton mechanism is shown in Eqs. (2)-(8); [21].

$$
\begin{gathered}
\mathrm{Fe}^{2+}+\mathrm{H}_{2} \mathrm{O}_{2} \rightarrow \mathrm{OH} \bullet+\mathrm{OH}^{-}+\mathrm{Fe}^{3+} \\
\mathrm{Fe}^{3+}+\mathrm{H}_{2} \mathrm{O}_{2} \rightarrow \mathrm{Fe}^{2+}+\mathrm{H}^{+}+\mathrm{HO}_{2} \bullet \\
\mathrm{Fe}^{3+}+\mathrm{HO}_{2} \bullet \rightarrow \mathrm{Fe}^{2+}+\mathrm{H}^{+}+\mathrm{O}_{2} \\
\mathrm{Fe}^{2+}+\mathrm{OH} \bullet \rightarrow \mathrm{Fe}^{3+}+\mathrm{OH}^{-} \\
\mathrm{OH} \bullet+\mathrm{OH} \bullet \rightarrow \mathrm{H}_{2} \mathrm{O}_{2} \\
\mathrm{OH} \bullet+\mathrm{H}_{2} \mathrm{O}_{2} \rightarrow \mathrm{H}_{2} \mathrm{O}+\mathrm{HO}_{2} \bullet \\
\mathrm{OH} \bullet+\text { organic molecules } \rightarrow \mathrm{CO}_{2}+\mathrm{H}_{2} \mathrm{O}
\end{gathered}
$$

According to Equations (2)-(8), ferrous ions initiate the reaction leading to generation of hydroxyl radicals, which 
then attact the organic pollutants cause their degradation [13], [21]. However, classical Fenton's reagent which is called as "homogeneous Fenton process" causes some important problems: (i) it must be separated to remove the iron ions so, leads to spend more time, more reagents and high investment cost, at the end of the reaction, (ii) the production of huge amounts of sludge and the formation of a high concentration of anions in the treated wastewater (iii) it is limited range of $\mathrm{pH}$ values ( $\mathrm{pH} 2-4)$ for reaction and (iv) the regeneration of catalyst is not possible due to deactivation because of the complexation with some iron complexing reagents, such as phosphate anions [13], [22]. In order to overcome these drawbacks of homogeneous Fenton process, a solid iron mineral can be used to replace the dissolved iron $\left(\mathrm{Fe}^{2+}\right)$ used in traditional homogeneous Fenton processes. Therefore, heterogeneous Fenton-like processes have been attract great attention as a more practical and economical alternative to homogeneous Fenton process.

The Fenton-like process was monitored by UV-vis spectral analysis. Changes in the absorption spectrum of BR 46 were given in Fig. 7, in the visible region, the broad band at $530 \mathrm{~nm}$ result from the conjugated $\pi$ system, linked by the two azo groups which are responsible for the colour of BR 46 dye. The absorption band declines and approximately disappears during the decolourisation, which is indicative of the azo dye degradation in terms of azo groups were totally broken. In addition to, new absorption bands appeared in the range of $300-340 \mathrm{~nm}$ indicated the formation of aromatic intermediates [4].

The $\mathrm{pH}$ is an important factor effect the catalytic activity, the activity of the oxidant and the substrate and the stability of hydrogen peroxide [11]. It was reported that, an increase in the $\mathrm{pH}$ of system leads to increase in the number of accessible iron sites in the catalyst, so higher reaction rates can be obtained as more hydroxyl radicals could be produced [9]. In addition that, it was reported that, unlike the traditional Fenton's reagent where the $\mathrm{pH}$ values have to be lowered less than 4 and the optimum $\mathrm{pH}$ value was reported as. 3.0 generally [11], [23]; the reaction between iron bearing minerals and hydrogen peroxide can effectively oxidize the organic molecules at circumneutral $\mathrm{pH}$ [24]. Therefore, no $\mathrm{pH}$ adjustment was made in this study. The $\mathrm{pH}$ of the solutions was measured at the start, pre-determined time intervals and end of the decolourisation. The measured pHs of BR 46 solutions in the range of $100-5000 \mathrm{mg} / \mathrm{L}$ concentration containing $5 \mathrm{~mL}$ of $10 \%(\mathrm{v} / \mathrm{v}) \mathrm{H}_{2} \mathrm{O}_{2}$ solution and appropriate amount of FeNPs were $4.86-4.45$ and $\mathrm{pH}$ values at the end of the decolourisation were measured as 4.33 - 4.07. FeNPs have quite fast and high decolourisation yields; > 95\%, the decolourisation yields were obtained all over the studied dye concentrations only at $5 \mathrm{~min}$ and almost completely at the at the end of 20 min reaction time and any significant fluctuation of $\mathrm{pH}$ was not measured at pre-determined time intervals.

The effect of FeNPs concentration on the BR46 decolourisation in the Fenton-like process was presented in Fig. 8, at the experimental conditions of initial BR 46 concentration: $100 \mathrm{mg} / \mathrm{L} ; \mathrm{H}_{2} \mathrm{O}_{2}$ volume: $5 \mathrm{~mL}$ of $10 \%$ (v/v); and temperature $298 \mathrm{~K}$. Five different FeNPs concentrations, in the range of $0.25-5 \mathrm{mg} / \mathrm{L}$ were selected to determine dye degradation efficiencies. In addition that, control experiment was performed only $5 \mathrm{~mL}$ of $10 \%$ (v/v) $\mathrm{H}_{2} \mathrm{O}_{2}$ containing dye solution without FeNPs added. As seen from Fig. 8, the control (free FeNPs concentration) showed nearly 11\% BR 46 dye decolourization efficiency. As can be seen from Fig. 8, the decolourisation percentage of BR 46 for FeNPs increased with increasing in FeNPs concentration from $0.25 \mathrm{~g} / \mathrm{L}$ to 0.5 $\mathrm{g} / \mathrm{L}$, which was mainly arise from the increase in the number of active sites of FeNPs and improving $\mathrm{H}_{2} \mathrm{O}_{2}$ decomposition and leads to the generation of more hydroxyl radicals. However, when the FeNPs concentrations were 1.0, 3.0, and $5.0 \mathrm{~g} / \mathrm{L}$, the decolourisation percentages were slightly remained constant. This may be due to the agglomeration of FeNPs and the scavenging of hydroxyl radicals through an undesired slow reaction was given in equation (9), [11].

$$
\mathrm{Fe}^{2+}+\mathrm{OH} \bullet \rightarrow \mathrm{Fe}^{3+}+\mathrm{OH}^{-}
$$

Therefore, in this study, the optimum FeNPs concentration was chosen as $0.5 \mathrm{~g} / \mathrm{L}$ for the rest of experiments.

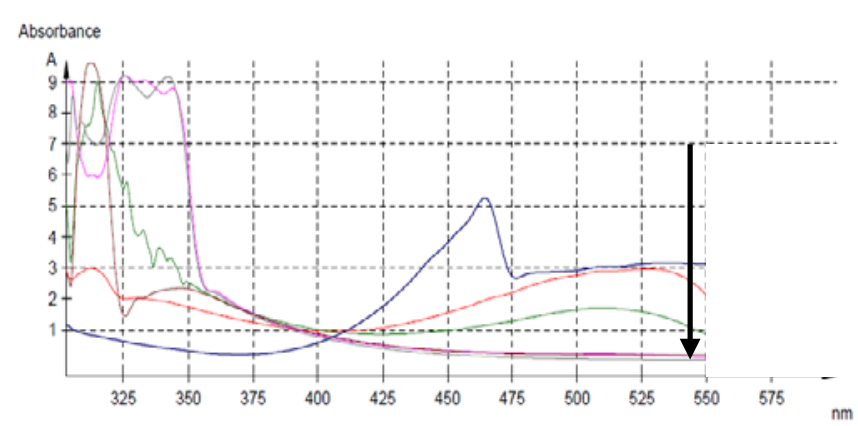

Fig. 7. The UV-vis spectra of BR46 dye after decolourisation by FeNPs (BR 46 concentration=200 mg/L).

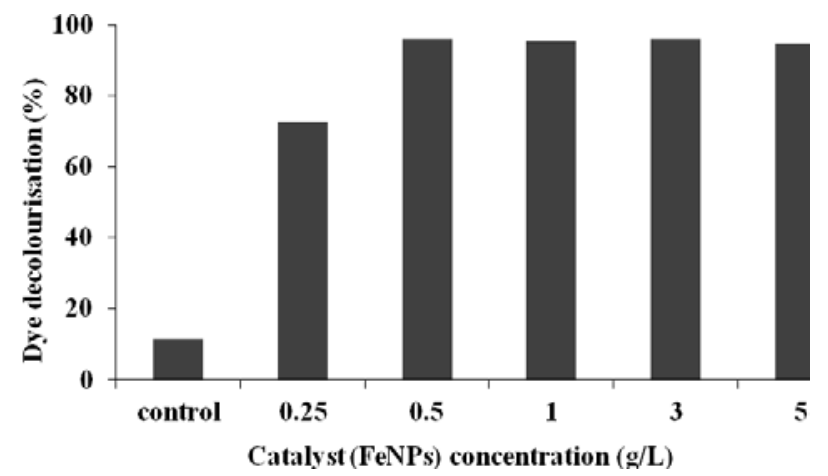

Fig. 8. The effect of FeNPs concentration on decolourisation (initial BR 46 concentration: $100 \mathrm{mg} / \mathrm{L} ; \mathrm{H}_{2} \mathrm{O}_{2}$ volume: $5 \mathrm{~mL}$ of $10 \%$ (v/v); and temperature $298 \mathrm{~K}$; control represents the dye solution without FeNPs added.).

The effect of initial dye concentration on BR 46 decolourisaton in Fenton-like system was shown in Fig. 9. As can be seen from Fig. 9, higher than 99\% decolourisation efficiencies were obtained and the decolourisation percentages increased by increasing the BR 46 concentration from $100 \mathrm{mg} / \mathrm{L}$ to $500 \mathrm{mg} / \mathrm{L}$ and then slightly remained constant with further increase in initial BR 46 concentration. This phenomenon can be explained by the concentration of BR 46 influencing the formation of hydroxyl radical and their scavengers. Less scavenging of hydroxyls radicals consisted of when initial organic substrate concentration increased without exceeding its optimum value [10]. Therefore, 500 $\mathrm{mg} / \mathrm{L}$ is within the optimal period for degradation which will 
avoid speed up the formation of radical $\mathrm{OH} \bullet$ scavengers.

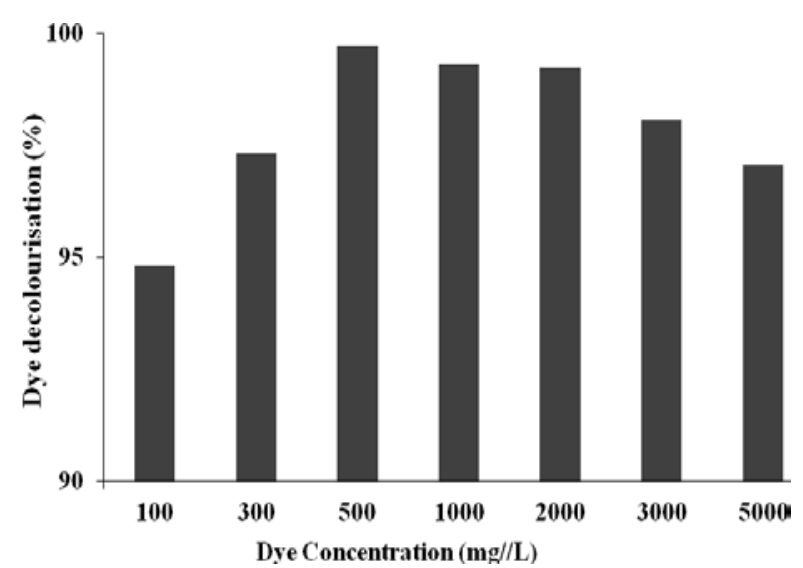

Fig. 9. The effect of initial dye concentration on decolourisaton (FeNPs concentration: $0.5 \mathrm{~g} / \mathrm{L}, \mathrm{H}_{2} \mathrm{O}_{2}$ volume: $5 \mathrm{~mL}$ of $10 \%(\mathrm{v} / \mathrm{v})$; and temperature $298 \mathrm{~K})$.

Also, the concentration of hydrogen peroxide influences the decolourisation efficiency directly too, since it is related to the amount of hydroxyl radicals produced in the Fenton-like reaction. The $5 \mathrm{~mL}$ of $10 \%(\mathrm{v} / \mathrm{v}) \mathrm{H}_{2} \mathrm{O}_{2}$ solution was used in all the decolourisation experiments provided the enough amounts of hydroxyl radicals for reaction as a result of obtaining almost completely dye decolourisation percentage at the end of reactions.

In this study, the synthesized FeNPs as shown in XRD pattern, consist of mainly iron oxide and iron oxohydroxide. As mentioned above, ferrous iron is replaced with iron oxide nanoparticles; the reaction is called Fenton-like. In the Fenton-like degradation process, the production of $\mathrm{Fe}^{2+}$ and $\mathrm{Fe}^{3+}$ in the solution depend on the ease of ferrous ion accessibility so, acidity is a significant factor.

In acidic medium, the surface of the iron oxide/oxohydroxide corrodes producing ferrous ions, these ions decompose hydrogen peroxide and provide the formation of $\mathrm{OH} \bullet$ radicals. These highly reactive $\mathrm{OH} \bullet$ radicals attack bonds in the dye molecules which might be in solution or adsorbed to the surface of the iron catalyst. In the case of, azo dyes such as BR 46, the cleavage of the azo band $(-\mathrm{N}=\mathrm{N}-)$ by $\mathrm{OH} \bullet$ in the chromophore of the dye leads to decolorization of the dye solution like this study [25].

Hence, based on the obtained results a possible Fenton-like reaction mechanism has been proposed similarly reported by Kuang et al. (2013), [11], in equations were given (10-17):

(i) Adsorption process:

$$
\begin{gathered}
\mathrm{BR} 46+\mathrm{FeNPs} \rightarrow \mathrm{BR} 46 / \mathrm{FeNPs} \\
\mathrm{BR} 46+\gamma-\mathrm{Fe}_{2} \mathrm{O}_{3} / \mathrm{Fe}_{3} \mathrm{O}_{4} \rightarrow \mathrm{BR} 46 / \gamma-\mathrm{Fe}_{2} \mathrm{O}_{3} / \mathrm{Fe}_{3} \mathrm{O}_{4}
\end{gathered}
$$

(ii) The process of producing hydroxyl radicals' species:

$$
\begin{gathered}
\mathrm{Fe}_{2} \mathrm{O}_{3} / \mathrm{Fe}_{3} \mathrm{O}_{4}+\mathrm{H}^{+} \rightarrow \mathrm{Fe}^{2+} / \mathrm{Fe}^{3+}+\mathrm{H}_{2} \mathrm{O} \\
\mathrm{Fe}^{2+}+\mathrm{H}_{2} \mathrm{O}_{2} \rightarrow \mathrm{Fe}^{3+}+\mathrm{OH} \bullet+\mathrm{OH}^{-} \\
\mathrm{Fe}^{2+} / \mathrm{Fe}^{3+}+\mathrm{H}_{2} \mathrm{O} \rightarrow \mathrm{FeOOH} \\
\mathrm{Fe}^{3+}+\mathrm{H}_{2} \mathrm{O}_{2} \rightarrow \mathrm{Fe}^{2+}+\mathrm{H}^{+}+\mathrm{HO}_{2} \bullet
\end{gathered}
$$

(iii) Hydroxyl radicals' species attack the BR46 on the surface of Fe NPs:

BR46/FeNPs $+\mathrm{OH} \bullet \rightarrow$ Reaction intermadiates/ FeNPs (iv) Reaction intermediates

$$
\mathrm{Fe}-\mathrm{NPs}+\mathrm{OH} \bullet \rightarrow \mathrm{CO}_{2}+\mathrm{H}_{2} \mathrm{O}
$$

There; at first, the BR 46 dye molecules were adsorbed onto the surface of FeNPs and $\gamma-\mathrm{Fe}_{2} \mathrm{O}_{3} / \mathrm{Fe}_{3} \mathrm{O}_{4}$ which were formed as a result of Fe corrosion, as suggested in Eqs. (10) and (11), [11], [24]. After that, $\mathrm{Fe}^{2+}$ and $\mathrm{Fe}^{3+}$ leached from iron oxides on the surface of FeNPs (12). This stage accelerated the decomposition of $\mathrm{H}_{2} \mathrm{O}_{2}$ and generated highly oxidative $\mathrm{OH} \bullet$ radicals when $\mathrm{Fe}^{2+}$ was oxidized by $\mathrm{H}_{2} \mathrm{O}_{2}$ into $\mathrm{Fe}^{3+}$; according to Fenton-like reaction (13). In the mean time, the generated $\mathrm{Fe}^{2+}$ and $\mathrm{Fe}^{3+}$ in the solution reacted with $\mathrm{H}_{2} \mathrm{O}$ and produced oxyhydroxide (14), which can also adsorb $\mathrm{BR}$ 46. Moreover, $\mathrm{Fe}^{3+}$ on the surface of FeNPs was converted into $\mathrm{Fe}^{2+}$ and $\mathrm{HO}_{2} \bullet$ (15). The produced $\mathrm{HO}_{2} \bullet$ probably further reacted with $\mathrm{Fe}^{3+}$ and it provided the decomposition of $\mathrm{H}_{2} \mathrm{O}_{2}$. However, the process of $\mathrm{Fe}^{3+}$ converting into $\mathrm{Fe}^{2+}$ was very slow.

When these ferrous ions, $\mathrm{Fe}^{2+}$ and $\mathrm{Fe}^{3+}$ were formed, $\mathrm{OH}$ • radicals reacted rapidly with the adsorbed BR 46 and attacked effectively on the bonds of the dye molecules. Finally a part of BR 46 was mineralized into $\mathrm{CO}_{2}$ and $\mathrm{H}_{2} \mathrm{O}$, on the surface of FeNPs $(16,17)$.

\section{CONCLUSIONS}

In this study, iron nanoparticles are mainly rich in iron oxides and iron oxohydroxide were prepared by using a non-toxic and cost-effective reducing agent, loquat leaves aqueous extract and the biosynthesized FeNPs were used as a heterogeneous Fenton-like catalyst for effective decolourisation of an azo dye, BR 46. According to characterization studies, iron nanoparticles were prepared succesfully and the synthesized nanoparticles have irregular spherical morfology as well as they are quite agglomerated. FT-IR analysis results showed that, BR 46 and/or its degradation products were adsorbed the FeNPs surface in consequence of the cleavage of the azo band $(-\mathrm{N}=\mathrm{N}-)$ in the chromophore of the dye, by $\mathrm{OH} \bullet$ radicals. The Fenton-like degradation was fairly fast and efficient dye decolourisation percentages (almost 100\%) were obtained for quite high concentrations of BR 46 in the range of $100-5000 \mathrm{mg} / \mathrm{L}$, at the end of the 20 min reaction time. The optimum Fenton-like decolourisation conditions were determined to be $500 \mathrm{mg} / \mathrm{L}$ of initial BR 46 concentration and $0.5 \mathrm{~g} / \mathrm{L}$ FeNPs (catalyst) concentration in the neutral $\mathrm{pHs}$ with the presence of $5 \mathrm{~mL}$ of $10 \%$ (v/v) $\mathrm{H}_{2} \mathrm{O}_{2}$ (oxidant) volume and $298 \mathrm{~K}$ temperature conditions. Therefore, the green synthesized FeNPs could be an excellent catalyst for decolourisation and removal of toxic dyes from aqueous solutions with Fenton-like degradation mechanism owing to their ease of production, high capability of decompose the hydrogen peroxide and formation the $\mathrm{OH} \bullet$ radicals for provide effective decolourisation and also; they can be readily separated from reaction medium after process.

\section{REFERENCES}

[1] A. Pokharia and S. S. Ahluwalia, "Biodecolorization and degradation of xenobiotic azo dye - Basic Red 46 by Staphylococcus epidermidis MTCC 1062,” Int. J. Res. Biosciences, vol. 5, no. 2, pp. 10-23, April 2016. 
[2] A. Truskewycz, R. Shukla, and A. S. Ball, "Iron nanoparticles synthesized using green tea extracts for the fenton-like degradation of concentrated dye mixtures at elevated temperatures," J. Environ. Chem. Eng., vol. 4, no. 4, pp. 4409 - 4417, December 2016.

[3] P. V. Nidheesh, R. Gandhimathi, and S. T. Ramesh, "Degradation of dyes from aqueous solution by Fenton processes: A review,” Environ. Sci. Pollut. Res., vol. 20, no. 4, pp. 2099-2132, April 2013.

[4] E. Guivarch, S. Trevin, C. Lahitte, and M. A. Oturan, "Degradation of azo dyes in water by electro-Fenton process," Environ. Chem. Lett., vol. 1, no. 1, pp. 38-44, February 2003.

[5] B. Gözmen, M. Turabik, and A. Hesenov, "Photocatalytic degradation of Basic Red 46 and Basic Yellow 28 in single and binary mixture by $\mathrm{UV} / \mathrm{TiO}_{2}$ /periodate system,” J. Hazard. Mater., vol. 164, no. 2, pp. 1487-149, May 2009.

[6] S. Chen, Y. Wu, G. Li, J. Wu, G. Meng, X. Guo, and Z. Liu, “A novel strategy for preparation of an effective and stable heterogeneous photo-Fenton catalyst for the degradation of dye," Appl. Clay Sci., vol. 136, pp. 103-111, February 2017.

[7] A. R. Khataee, "Photocatalytic removal of CI Basic Red 46 on immobilized $\mathrm{TiO}_{2}$ nanoparticles: Artificial neural network modeling," Environ. Technol., vol. 30, no. 11, pp. 1155-1168, September 2009.

[8] M. F. Hou, L. Liao, W. D. Zhang, X. Y. Tang, H. F. Wan, and G. C. Yin, "Degradation of rhodamine B by Fe (0)-based Fenton process with $\mathrm{H}_{2}$ $\mathrm{O}_{2}$," Chemosphere, vol. 83, no. 9, pp. 1279-1283, May 2011.

[9] I. Mazilu, C. Ciotonea, A. Chirieac, B. Dragoi, C. Catrinescu, A. Ungureanu, S. Petit, S. Royer, and E. Dumitriu, "Synthesis of highly dispersed iron species within mesoporous (Al-) SBA-15 silica as efficient heterogeneous Fenton-type catalysts,” Micropor. Mesopor. Mater., vol. 241, pp. 326-337, March 2017.

[10] R. Li, Y. Gao, X. Jin, Z. Chen, M. Megharaj, and N. Naidu, "Fenton-like oxidation of 2,4-DCP in aqueous solution using iron-based nanoparticles as the heterogeneous catalyst," J. Colloid Interface Sci., vol. 438, pp. 87-93, January 2015.

[11] Y. Kuang, Q. Wang, Z. Chen, M. Megharaj, and R. Naidu, "Heterogeneous Fenton-like oxidation of monochlorobenzene using green synthesis of iron nanoparticles,” J. Colloid Interface Sci., vol. 410, pp. 67-73, November 2013.

[12] Y. Hong, B. Lin, H. Cao, Y. Gao, and S. Lin, “Analysis of major triterpene acids and total polysaccharides in the leaves of 11 species of Eriobotrya,” in Proc. BIO Web of Conferences on EDP Sciences, 2017, vol. 8, p. 03012.

[13] T. Shahwan, S. A. Sirriah, M. Nairat, E. Boyacı, A. E. Eroğlu, T. B. Scott, and K. R. Hallam, "Green synthesis of iron nanoparticles and their application as a Fenton-like catalyst for the degradation of aqueous cationic and anionic dyes,” Chem. Eng. J., vol. 172, no. 1, pp. 258-266, August 2011.

[14] A. M. Awwad and N. M. Salem, "Kinetics and thermodynamics of Cd (II) biosorption onto loquat (Eriobotrya japonica) leaves,” J. Saudi Chem. Soc., vol. 18, no. 5, pp. 486-493, November 2014.

[15] A. Heller, M. S. Fleys, J. Chen, G. P. van der Laan, M. H. Rausch, and A. P. Fröba, "Thermal and mutual diffusivity of binary mixtures of n-dodecane and n-tetracontane with carbon monoxide, hydrogen, and water from Dynamic Light Scattering (DLS),” J. Chem. Eng. Data, vol. 61, no. 3, pp. 1333-1340, February 2016.

[16] M. Fazlzadeh, K. Rahmani, A. Zarei, H. Abdoallahzadeh, F. Nasiri, and R. A. Khosravi, "Novel green synthesis of zero valent iron nanoparticles (NZVI) using three plant extracts and their efficient application for removal of Cr (VI) from aqueous solutions," Adv. Powder Technol., vol. 28, no. 1, pp. 122-130, January 2017.

[17] T. Wang, X. Jin, Z. Chen, M. Megharaj, and R. Naidu, "Green synthesis of $\mathrm{Fe}$ nanoparticles using eucalyptus leaf extracts for treatment of eutrophic wastewater," Sci. Total Environ., vol. 466, pp. 210-213, January 2014.

[18] R. K. Gautam, V. Rawat, S. Banerjee, M. A. Sanroman, S. Soni, S. K. Singh, and M. C. Chattopadhyaya, "Synthesis of bimetallic Fe-Zn nanoparticles and its application towards adsorptive removal of carcinogenic dye malachite green and Congo red in water," J. Mol. Liq., vol. 212, pp. 227-236, December 2015.

[19] M. Iram, C. Guo, Y. Guan, A. Ishfaq, and H. Liu, “Adsorption and magnetic removal of neutral red dye from aqueous solution using $\mathrm{Fe}_{3} \mathrm{O}_{4}$ hollow nanospheres,” J. Hazard. Mater., vol. 181, no. 1, pp. 1039-1050, September 2010.
[20] F. Hussain, S. Guo, and G. Zhang, "Preparation and characterization of bifunctional Ti-Fe kaolinite composite for Cr (VI) removal,” J. Colloid Interface Sci., vol. 442, pp. 30-38, March 2015.

[21] A. Cihanoğlu, G. Gündüz, and M. Dükkanc1, "Degradation of acetic acid by heterogeneous Fenton-like oxidation over iron-containing ZSM-5 zeolites,” Appl. Catal., B: Environ., vol. 165, pp. 687-699, April 2015.

[22] J. Deng, J. Jiang, Y. Zhang, X. Lin, C. Du, and Y. Xiong, " $\mathrm{FeVO}_{4}$ as a highly active heterogeneous Fenton-like catalyst towards the degradation of Orange II,” Appl. Catal., B: Environ., vol. 84, no. 3, pp. 468-473, December 2008.

[23] E. G. Garrido-Ramírez, B. K. G. Theng, and M. L. Mora, "Clays and oxide minerals as catalysts and nanocatalysts in Fenton-like reactions-A review,” Appl. Clay Sci., vol. 47, no. 3, pp. 182-192, February 2010.

[24] X. Xue, K. Hanna, and N. Deng, "Fenton-like oxidation of Rhodamine B in the presence of two types of iron (II, III) oxide," J. Hazard. Mater., vol. 166, no. 1, pp. 407-414, July 2009.

[25] M. Kallel, C. Belaid, T. Mechichi, M. Ksibi, and B. Elleuch, "Removal of organic load and phenolic compounds from olive mill wastewater by Fenton oxidation with zero-valent iron,” Chem. Eng. J., vol. 150, no. 2, pp. 391-395, August 2009.

[26] Z. Wang, C. Fang, and M. Megharaj, "Characterization of iron-polyphenol nanoparticles synthesized by three plant extracts and their fenton oxidation of azo dye," ACS Sustainable Chem. Eng., vol. 2, no. 4, pp. 1022-1025, February 2014.

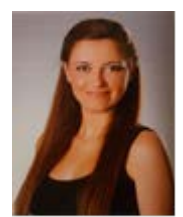

Emel Simla Önal is an undergraduate student at the Department of Chemical Engineering in Mersin University, Turkey. She studied on nanoparticle biosynthesis and characterization, heavy metal treatment by adsorption and textile dye degradation by Fenton-like process for her graduation thesis.

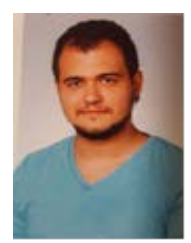

Tolga Yatkin is an undergraduate student at the Department of Chemical Engineering in Mersin University, Turkey. He studied on nanoparticle biosynthesis and characterization, heavy metal treatment by adsorption and textile dye degradation by Fenton-like process for his graduation thesis.

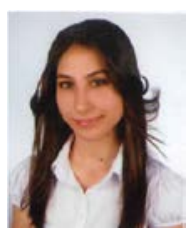

Memduha Ergüt is a $\mathrm{PhD}$ student and works as a research assistant at the Department of Chemical Engineering in Mersin University, Turkey. Her research activities are in the area of wastewater treatment, adsorption, material and nanomaterial synthesis and characterization.

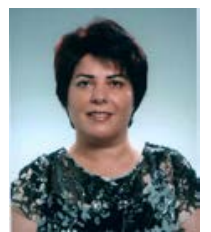

Ayla Özer is a professor of chemical engineering at the Department of Chemical Engineering in Mersin University, Turkey. She is also working as the head of this department. Her research activities are in the area of wastewater treatment, adsorption, kinetic modelling, material and nanomaterial synthesis and characterization. 